\title{
Challenges and Countermeasures on Human Resources Management of Catering Industry in China During the COVID-19 Epidemic
}

\author{
Yuting Zheng ${ }^{1, *}$ \\ ${ }^{1}$ Guangzhou Foreign Language School, Guangzhou 511458, China \\ *Corresponding author. Email: angela@cas-harbour.org
}

\begin{abstract}
The appearance of the COVID-19 epidemic has contributed to considerable impact on the human resources management in the catering industry. This article analyzes the challenges and opportunities of COVID-19 epidemic on the human resources management of hospitality industry in China, and recommends countermeasures of enterprises in aforementioned industry. The concepts are illustrated separately through detailed explanation, and a real-life business care is briefly discussed for each concept in order to demonstrate the practical applications of the theoretical ideas. It can be concluded that although some limitations have to be taken into consideration, these countermeasures can provide essential insights into human resources management and can effectively improve firms' management efficiency under COVID-19 epidemic.
\end{abstract}

Keywords: Managerial economics, Human resource management, COVID-19 epidemic, Catering industry.

\section{INTRODUCTION}

Under the impact of Covid-19, the service industry is facing severe challenges, especially China's leading industry — catering industry. The most distinctive characteristic of the catering industry is high turnover, and businesses are generally faced with the phenomenon of "three high and one low", such as high rent, high labor cost, high food material cost and low gross profit. In catering industry, the labor cost of the entire catering industry in China accounts for $21.11 \%$, and the rent cost accounts for $9.3 \%$, which totally account for a third of the total spending of catering business. Therefore, the control of those two costs is very important for the whole catering industry. Therefore, the author is interested in how human resource management could help catering industries face financial crisis. In the following parts, the challenges faced by catering industries as well as their countermeasures will be analyzed.

\section{OVERVIEW}

\subsection{Influence of COVID-19 on Chinese Industries}

Based on National Bureau of Statistics (NBS) [1], enterprises with losses of more than 100 accounted for more than $78 \%$ this year. According to the Henda Institute of Statistics [2], the catering industry in China suffered losses of $\$ 500$ billion in the Spring Festival (only 7 days). In China, in order to prevent the spread of COVID-19, many cities required local catering service units to suspend business, leading to a sharp decline in the business revenue of several catering businesses. Even though the landlord has reduced the rent burden, it still cannot offset the loss brought by COVID-19 to the enterprise.

In addition to the losses caused by high rental costs, COVID-19 has also led to a doubling of labor costs. When the epidemic was prevalent, local governments took special measures such as home quarantine and traffic restrictions. Since the outbreak began to improve, the state and governments at all levels have introduced various policies and measures 
on the resumption of work, and imposed strict requirements on enterprises to resume work. These policies and measures have played important roles in the prevention and control of the epidemic. However, they have also made it difficult for employees in the catering industry to resume work or return to work for some time. Therefore, the COVID-19 epidemic has caused a shortage of human resources in a short time. In this case, some human resource service enterprises take advantages of the opportunity to raise labor wages, which makes the human resource service enterprises need to pay higher labor costs. In addition, after the employees of these enterprises return to work, the human resource service enterprises need to carry out epidemic prevention and management, be equipped with necessary epidemic prevention equipment, and carry out staff health management, which increases the labor cost of enterprises to a certain extent.

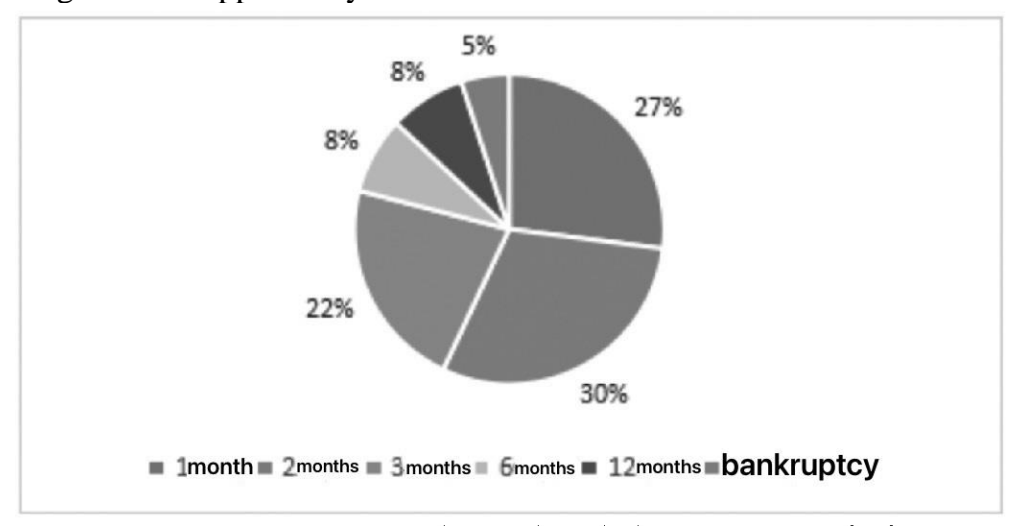

Figure 1 Months in which the enterprise's own cash flow can be made from March 1st, 2020 [3].

Table 1. Year-on-year sales release table for January and February 2020 [4]

\begin{tabular}{|l|r|r|}
\hline $\begin{array}{l}\text { Sales year-on-year } \\
\text { change range }\end{array}$ & $\begin{array}{l}\text { Percen tage of } \\
\text { fim s in January }\end{array}$ & $\begin{array}{l}\text { Percen tage of } \\
\text { fim s in February }\end{array}$ \\
\hline$(-100 \% \sim-90 \%)$ & $0.00 \%$ & $40.60 \%$ \\
\hline$(-90 \% \sim-80 \%)$ & $1.60 \%$ & $28.10 \%$ \\
\hline$(-80 \% \sim-70 \%)$ & $3.20 \%$ & $9.40 \%$ \\
\hline$(-70 \% \sim-60 \%)$ & $1.60 \%$ & $9.40 \%$ \\
\hline$(-60 \% \sim-50 \%)$ & $3.20 \%$ & $1.60 \%$ \\
\hline$(-50 \% \sim-40 \%)$ & $3.20 \%$ & $0.00 \%$ \\
\hline$(-40 \% \sim-30 \%)$ & $7.90 \%$ & $1.60 \%$ \\
\hline$(-30 \% \sim-20 \%)$ & $25.40 \%$ & $0.00 \%$ \\
\hline$(-20 \% \sim-10 \%)$ & $28.60 \%$ & $1.60 \%$ \\
\hline$(-10 \% \sim 0 \%)$ & $17.50 \%$ & $7.80 \%$ \\
\hline$(-0 \% \sim 10 \%)$ & $4.80 \%$ & $0.00 \%$ \\
\hline$(10 \% \sim 20 \%)$ & $1.60 \%$ & $0.00 \%$ \\
\hline$(20 \% \sim 30 \%)$ & $1.60 \%$ & $0.00 \%$ \\
\hline Total & $100 \%$ & $100 \%$ \\
\hline
\end{tabular}

Authorities released on February 6, 2020 that "About to do will be coronavirus pneumonia epidemic prevention and control work in relation to the human resources market management during the period of notice and so on", and these notifications include roughly requirements of human resources service enterprise to suspend recruitment and labor collaboration across regions, as well as offline clustering activities such as human resources training, to be postponed or cancelled the offline activities. To some extent, it has directly affected and restricted the normal business of human resource service enterprises.

The restaurant industry is also facing heavy losses from the accumulation of raw materials. Every year, the Spring Festival is a peak season for the catering industry. Before the Spring Festival, restaurants will estimate the passenger flow and store and pile up a lot of food materials in advance. Undoubtedly, this 
year is no exception. As early as in November 2019, restaurants began to stock up; but due to the impact of COVID-19, these materials are not needed at all, only to be discarded after their expiration in the warehouse. As money spent on food materials cannot be recovered, it led to the breakdown of the capital chain.

Because of the above reasons, the restaurant could not operate normally, which led to the rupture of capital chain. The restaurant had to delay the wages of employees, and the labor relations were tense. Moreover, due to the epidemic, many companies have reduced their employees' salaries in accordance with relevant regulations of the national and local governments, which has caused complaints and dissatisfaction among employees. Although the salaries of employees need to be paid are reduced, the enterprise still cannot afford all of them at the same time, so there are arrears in the payment of salaries to employees. The inability to pay salaries on time is a further strain on the already strained employee relations.

\subsection{Challenges and Opportunities for Catering Industry on Human Resources Management}

In the context of COVID-19 epidemic, industries that are dominated by online business scenarios, such as fresh e-commerce, online instant food shopping, take-out food delivery and other industries, have seen a favorable development situation. Many enterprises, which benefit from the epidemic, such as Freshhema, Meituan, ele. me and other platforms, have been short-staffed and other enterprises have seconded employees. These industries, which have developed well in the face of the epidemic, have provided the catering industry with opportunities to recruit and train its human resources. As a result, catering industries can develop new models of sharing employees.

As the online industry is booming, catering industry can choose to set up their own delivery industry. For restaurants, it is cost-effective for them to make delivery service, as renting employees out does not make as much money as doing takeout service by yourself. Besides, doing takeout by yourself can also build brand effect. Therefore, many enterprises choose to do takeout. In addition, during the period of COVID-19, people cannot go out to have dinner, thus catering company can actively be involved in delivery service for the government to share, take responsibility for the society, provide timely service for enterprise and laborer, play the advantages of the restaurant industry, such as the ability in aspects of recruitment, dispatch, outsourcing and professional level. All of these can make all levels of government and society to recognize the importance of catering enterprises to further improve so that the company would praise the government, society, enterprises and individuals in the image and value. It would also build brand effect and brand credibility, in order to bring the company more investment and better development in the future.

\section{COUNTERMEASURES FOR CATERING INDUSTRY}

\subsection{Sharing Employees}

To begin with, companies should choose to share their employees [5]. During the epidemic, the innovation of sharing employees between the catering industry and the new retail industry has been noticed and appreciated. Canteens that cannot open normally could borrow youth restaurant employees to Freshhema, and Freshheman could give assistance to help canteens achieve the growth order during the optimal allocation of human resources and solve the present situation of the shortage of staff, also ease the war "epidemic" food industry enterprise for the problem of the high cost of choose and employ persons, as more catering staff income provided safeguard.

Sharing employees can also be observed by the local government employees, the government will provide medical enterprise which demand labor to catering company, and catering company can send staff to these enterprises to carry out simple repetitive work for satisfying the shortage in labor. Wages can be paid by two firms, which can solve the problem of high labor cost and realize the value of the catering staff to create again. Companies can also open up new delivery businesses. In addition to sharing employees, the catering industry can adapt to the present market demand and start its new business of delivery. Customers can order from various delivery platforms, and the dishes will be delivered by the staff of the restaurant.

\subsection{Paying More Attention to Cash Flow}

Enterprises must pay attention to cash flow management to prevent the recurrence of the epidemic. Due to the direct and severe impact of the epidemic on the catering industry, there are still employee costs, part of rent costs and inventory costs 
during the closing period. After the resumption of business, the catering industry still experienced one to two quarters of digestion and recovery period, so this epidemic has a great impact and challenge on the cash flow and capital status of the catering industry, which have become the key factors for the catering industry to deal with this epidemic in terms of human resources. Enterprises should attach importance to cash flow management, take positive measures to face it and make good capital reserves and risk plans to prevent the occurrence of the epidemic.

Enterprises need to reserve a certain amount of working capital to maintain a healthy and stable cash flow, so as to cope with the subsequent possible needs and macro risks of business. As mentioned before, under the influence of policies related to the epidemic, enterprises cannot operate normally. However, rents and labor costs are still high, which leads to the subsequent breakdown of labor relations with employees, inability to pay wages, and the breakdown of capital chains. Therefore, under normal circumstances, enterprises should meet their capital needs for at least three months to avoid sudden economic crisis.

\subsection{Establishing Risk Management System}

Catering enterprises should also establish risk management system and contingency plan mechanism, so as to cope with the black swan event and add flexible clauses in the contract. COVID-19 is like a black swan event with huge unexpected and huge impact. However, subsequent economists believe that the risks and challenges faced by the catering industry under COVID-19 are explainable and predictable. According to a related study [6], the COVID-19 outbreak changed the original structure of the industry-related network, which shifted to a star network structure with leisure services at the core. Therefore, the enterprise should do a good job in capital flow management to improve capital utilization. Enterprises should strictly control the inventory turnover period and receivables payback period; meanwhile extend the payable turnover period, so as to reduce the cash cycle and improve the cash flow rate of enterprises.

The state should also join in and encourage financial institutions to help enterprises deal with black swan events. For example, insurance companies can think about setting up innovative insurance to help catering enterprises deal with emergencies such as the sudden epidemic. The government could set up special COVID-19 subsidies for services, although the subsidies may lead to a large amount of government spending.

\subsection{Building Strong Labor Relations}

In human resource management, labor relations are also very important. Harmonious and good employee relations are the strong support of the enterprise. Good labor-management relations are particularly important when environmental catastrophe, business and human resource management are facing changes and challenges, whether during or after an epidemic, so the enterprise should manage the harmonious employee relation well. It is very difficult for employees to return to work under the epidemic, so it is necessary to provide them with unexpected medical insurance costs and vacation wages, to eliminate employees' worries about the company's intensive labor force, treatment costs and wages. This behavior can provide employees with security so that they can return to work more confidently, thus improving their work efficiency.

\section{DISCUSSION}

\subsection{Importance of Health Labor Relationship}

First of all, human resource service enterprises should resume work in accordance with the relevant requirements of the government. In addition, in order to ensure that employees can return to work well, human resource service enterprises need to do a good job in the protection of basic measures. Doing a good job in caring for employees during the epidemic period can increase their sense of security and sense of belonging, and make them feel at ease to return to work and resume work.

\subsection{Export Food Materials (in Canteen or Online)}

Catering companies can also take the following measures to reduce the negative impact of the epidemic. Companies can increase export of food materials. Under the epidemic situation, many enterprises were forced to throw away a large amount of food materials because of their expired and deteriorated, causing a lot of losses and injuries to enterprises. Enterprises can actually take the food under the condition of not bad for secondary sales to put the ingredients to the surrounding residents, and use the spare room for the dishes at a discount or processed into medium. This method can neither 
waste food caused heavy losses and can also make up for some money as well as make full use of the human resources of enterprises. They can also sell them on some take-out apps to make use of Internet resources and create a unique Internet brand effect.

\subsection{Structural Reform of Human Resource Management}

Companies also need to train their human resources. After the outbreak of the epidemic, the hotel and catering industry are facing the pressure of structural adjustment, transformation and upgrading. As knowledgeable, professional and skilled personnel are the fundamental driving force for the development of the industry, enterprises should enhance the level of modernization of the hotel and catering industry service, strengthen the degree of training attention, encourage online training, and improve the utilization efficiency of human resources in the industry. At the same time, highly skilled personnel can also bring the possibility of the transformation of intelligent restaurants, so enterprises should always have high requirements for high-quality human resources.

\section{CONCLUSION}

The current shortage mainly focuses on the conflict between the still high human cost and insufficient cash flow under the epidemic, and some solutions to this problem are proposed above. Catering companies can take following actions to tackle with problems, including launching take-out services, lending employees out to companies the catering companies and pharmaceutical companies that need staff, selling unsold raw materials in stores, focusing on cash flow, and building good labor relations. However, enterprises are still faced with great challenges. The market is limited, although their own market share growth is stable, others are in the case of growing, so enterprises need to increase revenue and reduce expenditure and prices to compete for market share, in order to obtain longterm profits. Moreover, such measures serve as the introduction of take-out service require time and high cost, which may lead to more expenses for catering companies in the short term. There are still many shortcomings in this paper, because there is no actual investigation on all large companies that face cost shortage. In the future, the author will investigate a specific company and make improvements as well as adjustments according to the actual situation.

\section{ACKNOWLEDGMENTS}

In writing this paper, I have got the help of two thesis teachers. Here I would like to thank them for their guidance and correction of my outline, which enabled me to write the paper smoothly. I would also like to thank the various contributors to the online literature who have allowed me to look up sources to express the methods I want to describe. Thanks to my advisor, who taught me a lot about management economic.

\section{AUTHORS' CONTRIBUTIONS}

This paper is independently completed by Yuting Zheng.

\section{REFERENCES}

[1] Survey of National Bureau of Statistics in the first half of 2020, 2020.

[2] Survey of Henda Institute of Statistics in 2020, retrieved from http://food.china.com.cn/202009/02/content_76662726.htm, accessed on December 10th, 2020.

[3] China Chain Operation Association reports on the cash flow of 71 chain restaurant groups, March 2020, from official website of Food Business, accessed on December 10th, 2020

[4] China Chain Operation Association reports on the turnover of catering employees from January to February 2020, from the electronic version of China Food Newspaper 2nd released on March 20th, 2020, accessed on December 10th, 2020.

[5] Shi Yunyi, Li Yanli. The influence of the Covid-19 on the development of Chinese catering industry and its countermeasures, Business School of Guilin University of Technology, Modern Business, 2021(01).

[6] Li Zhongfei, Qi Zhou, Ming Chen, Qian Liu, The impact of COVID-19 on industry-related characteristics and risk contagion, Finance Research Letters, Vol 39, p.101931, 2021. 